\title{
Shoulder Activity Level is Associated With Type of Employment and Income in the Normative Population Without Shoulder Disorders
}

\author{
Robert H. Brophy MD, Kenneth M. Lin BS, S. Andrew Skillington BS, \\ C. Tate Hepper MD, Matthew V. Smith MD
}

Received: 25 February 2016/Accepted: 13 June 2016/Published online: 27 June 2016

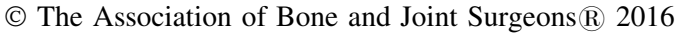

\begin{abstract}
Background Socioeconomic variables influence various healthcare issues in different ways. The effect of socioeconomic variables on the shoulder has not been well studied. Because activity level, defined by how much a patient actually does, is an important patient outcome measure and prognostic factor for the shoulder, studying its association with occupation and income will advance our understanding of how these variables relate to shoulder disorders, treatments, and outcomes.

Questions/purpose We asked: (1) Does shoulder activity score correlate with income level, stratified by gender? (2) Do different employment groups-heavy, moderate, light, student, retired-have different shoulder activity scores, as stratified by gender? (3) Is type of sports participation
\end{abstract}

Each author certifies that he or she, or a member of his or her immediate family, has no funding or commercial associations (eg, consultancies, stock ownership, equity interest, patent/licensing arrangements, etc) that might pose a conflict of interest in connection with the submitted article.

All ICMJE Conflict of Interest Forms for authors and Clinical Orthopaedics and Related Research ${ }^{\circledR}$ editors and board members are on file with the publication and can be viewed on request.

Each author certifies that the study institution approved or waived approval for the reporting of this investigation and that all investigations were conducted in conformity with ethical principles of research.

The study was completed at the Washington University School of Medicine.

R. H. Brophy ( $\bowtie)$, K. M. Lin, S. A. Skillington, M. V. Smith Department of Orthopaedic Surgery, Washington University School of Medicine, 14532 S. Outer Forty Drive, Chesterfield, MO 63017, USA

e-mail: brophyr@wudosis.wustl.edu

C. T. Hepper

OrthoVirginia, Arlington, VA, USA (contact or overhead) associated with income level, employment type, race, or household size?

Methods A survey collected the Brophy and Marx shoulder activity score and demographic information, such as age, gender, race, income, type of employment, and household size from 1625 individuals 18 years and older with no current or previous shoulder pain or injury who are members of a research panel matched to the United States population by age, gender, household income and size, race/ethnicity, and geography. Men and women were analyzed separately. Activity level was controlled for age. Results Shoulder activity correlated with income level among men $(\mathrm{R}=0.03 ; \mathrm{p}<0.001)$ and women $(\mathrm{R}=0.06$; $\mathrm{p}=0.0002$ ). For men, heavy employment had the highest Shoulder Activity Scale (SAS) level (12.1 \pm 4.9$)$, which was more than SAS levels in sedentary $(9.1 \pm 4.5$; mean difference, 3.0; 95\% CI, 2.5-3.6; $\mathrm{p}=0.001)$, student ( $8.8 \pm$ 5.1; mean difference, 3.3; 95\% CI, 3.0-3.7; $\mathrm{p}=0.007$ ), retired $(8.0 \pm 4.6$; mean difference, $4.1 ; 95 \%$ CI, 3.6-4.7; $\mathrm{p}=0.0001)$, and not working ( $7.5 \pm 5.3$; mean difference, 4.6 ; 95\% CI, 4.6-4.6; $\mathrm{p}<0.001)$ categories; similarly, for women, heavy employment had the highest SAS level $(12.0 \pm 5.8)$. However, as there were few women working in heavy labor, the only significant difference in women was between moderate employment $(8.8 \pm 4.2)$ and sedentary employment $(7.0 \pm 4.1$; mean difference, 1.8 ; 95\% CI, 1.6-1.9; $\mathrm{p}=0.0015)$. Participation in contact $(19.9 \%$ vs $12.0 \% ; p=0.006)$ and overhead sports $(25.2 \%$ vs $14.2 \% ; \mathrm{p}<0.001)$ was greater among males with higher incomes.

Conclusions Shoulder activity level is related to the socioeconomic factors of income and type of employment. Heavy laborers have higher shoulder activity level, likely directly related to their work. Individuals with higher incomes also have higher shoulder activity level, probably 
attributable to recreation as evidenced by their greater participation in contact and overhead sports. Independent of the underlying cause, these patients probably are more likely to seek treatment for shoulder disorders and may be more challenging to treat because of their elevated activity level. Future research should focus on how elevated activity level in these populations affects their risk for shoulder disorders, and their use of and outcomes from treatment for these disorders.

Level of Evidence Level IV, prognostic study

\section{Introduction}

Activity level can be a valuable prognostic factor that predicts patient outcomes. For example, activity level is a major predictor of graft failure after ACL reconstruction [15], implant wear in total joint arthroplasty [16], and success of microfracture treatment for osteochondral defects in the knee [11]. Previous studies have suggested lower back and neck-shoulder pain vary with socioeconomic status [18], and some have investigated job-related risk factors for shoulder symptoms in construction [3], and computer desk [9] occupations. In the shoulder, substantial variance in activity scores is seen in age- and diagnosismatched cohorts, suggesting that shoulder activity level may be influenced by other patient variables such as employment and socioeconomic status. Additionally, age, gender, and medical comorbidities affect shoulder activity in patients with rotator cuff tears [5].

Currently, there are few data on the relationship of socioeconomic variables with an individual's activity level. Although some studies have reported on activity scales in various anatomic areas as outcome measures and prognostic factors $[11,15,16]$, few studies explicitly identify specific patient variables associated with or predictive of activity level [5, 13]. Identifying predictors of activity level enhances the application and interpretation of activity level in clinical studies. Shoulder activity has been shown to be lower in women than men and decreases with age [13]. Socioeconomic variables may contribute to these differences, for example, if fewer women work in occupations with heavy labor. To our knowledge, no studies have been published regarding the relationship of shoulder activity level with socioeconomic variables. Patients with higher incomes may be more likely to participate in shoulder-focused activities such as golf, swimming, and tennis. The variance in activity level could have important implications regarding the incidence of shoulder disorders, the likelihood of seeking treatment for shoulder disorders, and the outcomes from treatment of shoulder disorders.
Therefore, we asked: (1) Does the shoulder activity score correlate with income level, stratified by gender? (2) Do different employment groups-heavy, moderate, light, student, retired-have different shoulder activity scores, as stratified by gender? (3) Is the type of sports participation (contact or overhead) associated with income level, employment type, race, or household size?

\section{Materials and Methods}

After approval by the local institutional review board, survey participants were drawn from TNS Global (London, United Kingdom), as described in a study focusing on patient age and gender [13]. The TNS Research Panel is matched to the March 2010 Current Population Survey (CPS) Social and Economic Supplement data [20] and the 2009 American Community Survey (ACS) [21] based on age, gender, household income, household size, race/ethnicity, and geography through demographic databases. Of 2773 panel members invited to participate, 2403 completed an email survey including the validated shoulder activity score [4]. The panel is matched to the CPS and ACS and represents the overall population as a whole. The $87 \%$ of the panel who responded have the same distribution as the complete panel. Participants were not compensated directly for this study but are incentivized as members of the Panel.

The Shoulder Activity Scale (SAS) (Fig. 1) evaluates a patient's overall shoulder activity level based on the frequency with which he or she completes five common activities of the shoulder. Frequency for each item is scored from 0 to 4 in increments of 1 , with each point corresponding to a category of increasing frequency: never or less than once a month, once a month, once a week, more than once a week, or daily. The total numerical activity score is the sum of the individual item scores, ranging from a minimum of 0 points (if a patient answers "never or less than once a month" for all five items) to a maximum of 20 points (if the patient answers "daily" for all five items). Because the activity scale is designed to measure patients' overall level of activity, patients are asked to indicate how often they performed each activity during their healthiest and most active state in the previous year. Previous studies using the SAS have shown its reliability, validity, and responsiveness $[4,5,19]$. Among subjects with no history of shoulder symptoms or treatment for a shoulder condition, the shoulder activity score decreases with age and is lower in women than men [13]. In patients with shoulder disorders, the shoulder activity score is highest in patients with shoulder instability, intermediate in patients with rotator cuff disease, and lowest in patients with shoulder osteoarthritis [19]. In addition, patients are asked two 
Fig. 1 The Shoulder Activity Scale is shown. (Published with permission from Wolters Kluwer Health Inc from Brophy $\mathrm{RH}$, Beauvais RL, Jones EC, Cordasco FA, Marx RG. Measurement of shoulder activity level. Clin Orthop Relat Res. 2005;439:101-108.).
Please indicate with an "X" how often you performed each activity in your healthiest and most active state, in the past year.

\begin{tabular}{|l|l|l|l|l|l|}
\hline & $\begin{array}{l}\text { Never or less than } \\
\text { once a month }\end{array}$ & $\begin{array}{l}\text { Once a } \\
\text { month }\end{array}$ & $\begin{array}{l}\text { Once a } \\
\text { week }\end{array}$ & $\begin{array}{l}\text { More than } \\
\text { once a week }\end{array}$ & Daily \\
\hline $\begin{array}{l}\text { Carrying objects 8 pounds or } \\
\text { heavier by hand (such as a bag } \\
\text { of groceries) }\end{array}$ & & & & & \\
\hline Handling objects overhead & & & & & \\
\hline $\begin{array}{l}\text { Weight lifting or weight training } \\
\text { with arms }\end{array}$ & & & & & \\
\hline $\begin{array}{l}\text { Swinging motion (as in hitting a } \\
\text { tennis ball, golf ball, baseball, } \\
\text { or similar object) }\end{array}$ & & & & & \\
\hline $\begin{array}{l}\text { Lifting objects 25 pounds or } \\
\text { heavier (such as 3 gallons of } \\
\text { water) NOT INCLUDING } \\
\text { WEIGHT LIFTING }\end{array}$ & & & & & \\
\hline
\end{tabular}

For each of the following questions, please circle the letter that best describes your participation in that particular activity.

1) Do you participate in contact sports (such as, but not limited to, American football, rugby, soccer, basketball, wrestling, boxing, lacrosse, martial arts, etc.)?
A No
B Yes, without organized officiating
C Yes, with organized officiating
D Yes, at a professional level (i.e. paid to play)

2) Do you participate in sports that involve hard overhand throwing (such as baseball, cricket, or quarterback in American football), overhead serving (such as tennis or volleyball), or lap/distance swimming?
A No
B Yes, without organized officiating
C Yes, with organized officiating
D Yes, at a professional level (i.e. paid to plav)

multiple-choice questions regarding level of sports participation (without organized officiating, with organized officiating, or at a professional level) in contact and overhead-throwing sports.

Survey quotas were set at 300 participants for four age categories (18-30 years, 31-50 years, 51-70 years, and older than 70 years) for men and women. Potential participants of each age and gender category were excluded once the corresponding quota was met. Participants were excluded based on failure to complete the entire survey, age younger than 18 years, or inability to read or understand the questionnaire. TNS Global provided a clean data file using commercially available software (Microsoft $^{\circledR}$
Excel $^{\circledR}$, Redmond, WA, USA) after the surveys were completed. There was no incentive for participation.

The study was designed to assess whether the shoulder activity score was associated with: (1) income level, (2) type of employment, (3) race, and (4) household size. Income level was segregated by annual income as less than USD 30,000 , USD 30,000 to 49,999 , USD 50,000 to 74,999 , and USD 75,000 or more. Employment was categorized as heavy (construction), moderate (nursing, waiter, retail), sedentary (office work, business, law), student, retired, and not working. Race was defined as white, black, and other. Household size was defined as one, two, three, or more. 
Of the 2773 eligible participants, 2403 completed the entire survey and were included. Of this group, participants who reported a history of shoulder symptoms or treatment were excluded from analysis, leaving 1625 participants as healthy controls. Summary statistics are available for men (Table 1) and women (Table 2).

\section{Statistical Analysis}

Rank-transformed shoulder activity scores were compared using generalized linear models. Income was treated as an ordinal linear variable from the lowest category to the highest category and analyzed by linear regression. Employment type, race, and household size categories were analyzed using ANOVA with post hoc comparisons of all groups performed with the Tukey-Kramer adjustment for multiple comparisons. Age category was included in all models as an ordered covariate. Men and women were analyzed separately. Chisquare analysis was used to compare the percentage of participants involved in contact and overhead sports.

\section{Results}

Shoulder activity correlated with income level among men $(\mathrm{p}<0.001)$ and women $(\mathrm{p}=0.002$ (Fig. 2). For men, the shoulder activity score in the highest income group

Table 1. Summary statistics for the shoulder activity score in men

\begin{tabular}{lcc}
\hline Variable & Number of participants & Mean \pm SD \\
\hline Overall & 800 & $9 \pm 5$ \\
Income & & \\
< USD 30,000 & 140 & $7.8 \pm 5.2$ \\
USD 30,000-49,999 & 167 & $8.6 \pm 4.8$ \\
USD 50,000-74,999 & 152 & $9.3 \pm 4.7$ \\
$\geq$ USD 75,000 & 341 & $9.6 \pm 4.6$ \\
Employment & & \\
Heavy & 69 & $12.1 \pm 4.9$ \\
Moderate & 129 & $10.2 \pm 4.3$ \\
Sedentary & 232 & $9.1 \pm 4.5$ \\
Student & 48 & $8.8 \pm 5.1$ \\
Retired & 243 & $8.5 \pm 4.6$ \\
Not working & 79 & $7.5 \pm 5.3$ \\
Race & & \\
White & 667 & $9.1 \pm 4.8$ \\
Black & 69 & $8.4 \pm 5.3$ \\
Other & 56 & $8.6 \pm 4.3$ \\
Household size & & \\
1 & 135 & $9.4 \pm 5.0$ \\
2 & 296 & $9.0 \pm 4.6$ \\
3+ & 365 &
\end{tabular}

( $>$ USD 75,000) was $9.6 \pm 4.6$, whereas that of the lowest group ( $<$ USD 30,000) was $7.8 \pm 5.2$; and for women, they were $8.2 \pm 4.3$ and $6.4 \pm 4.2$, respectively.

For men, heavy employment had the highest shoulder activity score $(12.1 \pm 4.9)$, which was more than the scores for sedentary $(9.1 \pm 4.5$; mean difference, $3.0 ; 95 \% \mathrm{CI}$, 2.5-3.6; $\mathrm{p}=0.001)$, student $(8.8 \pm 5.1$; mean difference, $3.3 ; 95 \%$ CI, 3.0-3.7; $\mathrm{p}=0.007)$, retired (8.0 \pm 4.6 ; mean difference, 4.1; 95\% CI, 3.6-4.7; p < 0.001), and not working (7.5 \pm 5.3 ; mean difference, 4.6 ; shoulder activity score $(12.0 \pm 5.8)$ (Table 3$)$. In men, the shoulder activity score in the moderate group $(10.2 \pm 4.3)$ also was more than the score for the retired group (mean difference, 2.2; 95\% CI, 2.1-2.4; $\mathrm{p}=0.020$ ) and the not working group (mean difference, 2.7; 95\% CI, 2.3-3.1; $\mathrm{p}<0.001$ ); and the score in the sedentary group was more than the score for those not working (mean difference, 1.6; 95\% CI, 1.0-2.1; $\mathrm{p}=0.037)$. The shoulder activity score in women with moderate employment $(8.8 \pm 4.2)$ was more than the score for those with sedentary employment (mean difference, 1.8; 95\% CI, 1.6-1.9; $\mathrm{p}=0.002)$.

Participation in contact $(\mathrm{p}=0.006)$ and overhead sports $(\mathrm{p}<0.001)$ was greater among males with higher incomes (Table 4). No such difference was observed for women in different income groups (Fig. 3). Participation in contact and overhead sports did not differ by type of employment, race, or household size.

Table 2. Summary statistics for shoulder activity score in women

\begin{tabular}{lcc}
\hline Variable & Number & Mean \pm SD \\
\hline Overall & 825 & $7 \pm 4$ \\
Income & & \\
$<$ USD 30,000 & 215 & $6.4 \pm 4.2$ \\
USD 30,000-49,999 & 163 & $6.8 \pm 4.5$ \\
USD 50,000-74,999 & 142 & $7.5 \pm 4.4$ \\
$\geq$ USD 75,000 & 305 & $8.2 \pm 4.3$ \\
Employment & & \\
Heavy & 7 & $12.0 \pm 5.8$ \\
Moderate & 141 & $8.8 \pm 4.2$ \\
Sedentary & 242 & $7.0 \pm 4.1$ \\
Student & 64 & $8.3 \pm 4.9$ \\
Retired & 218 & $6.1 \pm 4.0$ \\
Not working & 153 & $7.6 \pm 4.7$ \\
Race & & \\
White & 684 & $7.4 \pm 4.3$ \\
Black & 80 & $7.0 \pm 5.0$ \\
Other & 54 & $6.5 \pm 4.7$ \\
Household size & & $6.3 \pm 4.0$ \\
1 & 135 & $6.9 \pm 4.2$ \\
2 & 296 & \\
3+ & 365 & \\
\hline
\end{tabular}


OMen owomen

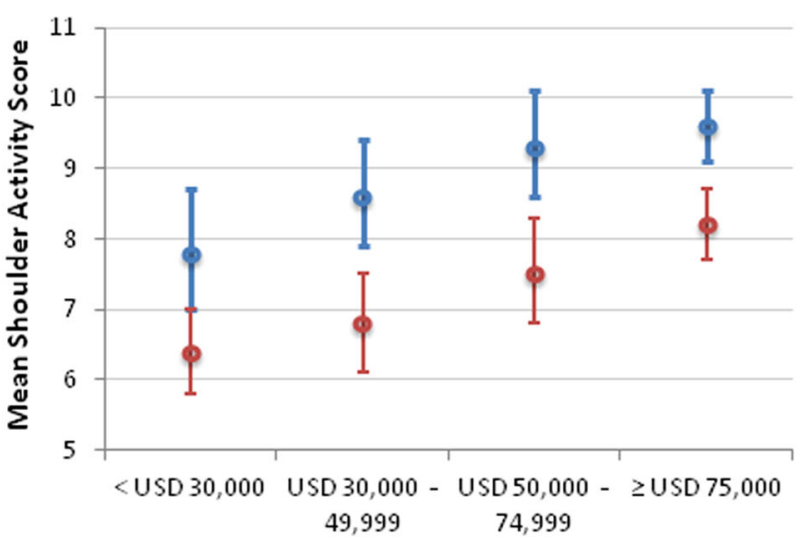

A

Income omen owomen

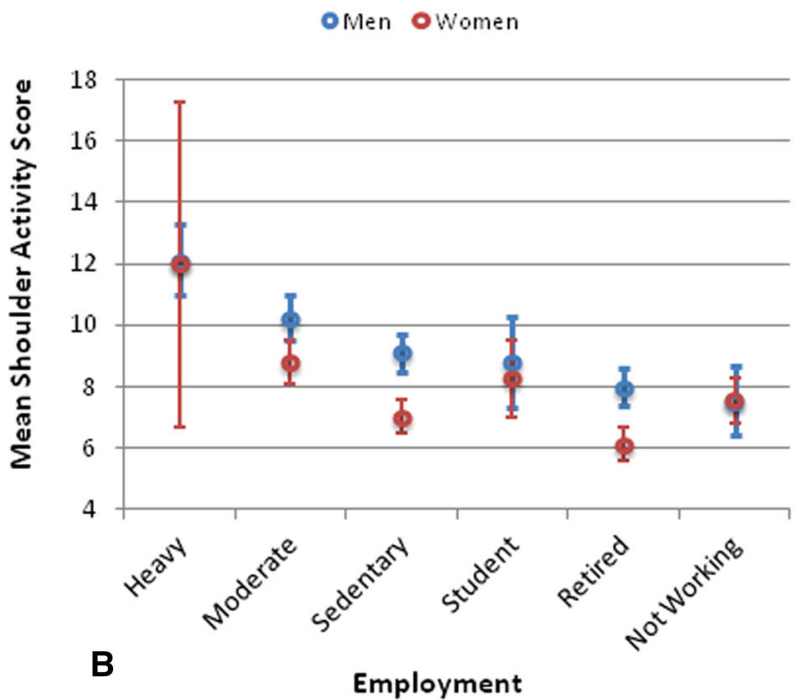

( $p=0.0004)$ and women $(p=0.0002)$. (B) By ANOVA, the score is related to employment in men $(\mathrm{p}<0.0001)$ and women $(\mathrm{p}=0.0006)$.
Fig. 2A-B Means with 95\% CIs of the shoulder activity score by socioeconomic and occupational variables are shown. (A) By linear regression, the shoulder activity score is related to income in men

Table 3. Probability values from post hoc comparisons of mean scores among employment groups

\begin{tabular}{|c|c|c|c|c|c|c|}
\hline Gender & Employment group & Moderate & Sedentary & Student & Retired & Not working \\
\hline \multirow[t]{5}{*}{ Men } & Heavy & 0.299 & $0.001 *$ & $0.007 *$ & $0.0001 *$ & $<0.0000^{*}$ \\
\hline & Moderate & & 0.272 & 0.347 & $0.021 *$ & $0.0002 *$ \\
\hline & Sedentary & & & 0.983 & 0.614 & $0.037 *$ \\
\hline & Student & & & & 0.999 & 0.687 \\
\hline & Retired & & & & & 0.812 \\
\hline \multirow[t]{5}{*}{ Women } & Heavy & 0.511 & 0.054 & 0.156 & 0.099 & 0.136 \\
\hline & Moderate & & $0.002 *$ & 0.439 & 0.088 & 0.155 \\
\hline & Sedentary & & & 0.955 & 0.998 & 0.808 \\
\hline & Student & & & & 0.999 & 1.000 \\
\hline & Retired & & & & & 0.992 \\
\hline
\end{tabular}

* Statistically significant.

\section{Discussion}

Occupational and socioeconomic factors have been linked to shoulder disorders $[1,3,6,7,9,14,18]$. Musculoskeletal symptoms have been associated with factors such as income, educational attainment, physical demand of labor, and lack of health insurance [7]. Many studies have implicated type and volume of work as crucial factors for studying occupational and socioeconomic impact on shoulder symptoms $[1,3,6,7,9,14,18]$, but to our knowledge, no such studies have formally evaluated the role of shoulder activity level. Therefore, we aimed to study the association of socioeconomic factors with shoulder activity score in individuals without current or previous shoulder pain or injury.
Our study has numerous limitations. Although a crosssectional design was used with a database matched to the United States Census Bureau on geographic region, age, income, and household size, the sample size is relatively small compared with the total US population. However, the response rate was high $(86 \%)$. It is possible that other unknown confounders of activity level are important and should have been accounted for. Because subjects were recruited based on age and sex quotas, certain socioeconomic populations were underrepresented compared with others (for instance, women in heavy labor, and nonwhite racial groups). Participants were recruited via email, potentially introducing selection bias. Although it is unlikely that familiarity with technology influences shoulder activity, this approach could have biased the study 
Table 4. Participation in contact and overhead sports by income and gender*

\begin{tabular}{|c|c|c|c|c|}
\hline Variable & Income $\leq$ USD 30,000 & USD 30,000-49,999 & USD 50,000-74,999 & $\geq \operatorname{USD} 75,000$ \\
\hline \multicolumn{5}{|l|}{ Contact sports } \\
\hline Male yes (\%) & $21 / 140(15 \%)$ & $14 / 167(8 \%)$ & $20 / 152(13 \%)$ & $68 / 341(20 \%)$ \\
\hline Male no $(\%)$ & $119(85 \%)$ & $153(92 \%)$ & $132(87 \%)$ & $273(80 \%)$ \\
\hline Female yes $(\%)$ & $11 / 215(5 \%)$ & $13 / 163(8 \%)$ & $9 / 142(6 \%)$ & $28 / 305(9 \%)$ \\
\hline Female no $(\%)$ & $204(95 \%)$ & $150(92 \%)$ & $133(94 \%)$ & $277(91 \%)$ \\
\hline \multicolumn{5}{|l|}{ Overhead sports } \\
\hline Male yes $(\%)$ & $18 / 140(13 \%)$ & 21/167 (13\%) & $26 / 152(17 \%)$ & $86 / 341(25 \%)$ \\
\hline Male no $(\%)$ & $122(87 \%)$ & $146(87 \%)$ & $126(83 \%)$ & $255(75 \%)$ \\
\hline Female yes (\%) & $17 / 215(8 \%)$ & $14 / 163(9 \%)$ & $12 / 142(9 \%)$ & $42 / 305(14 \%)$ \\
\hline Female no $(\%)$ & $198(92 \%)$ & $149(91 \%)$ & $130(91 \%)$ & $263(86 \%)$ \\
\hline
\end{tabular}

* Raw counts and percentages.

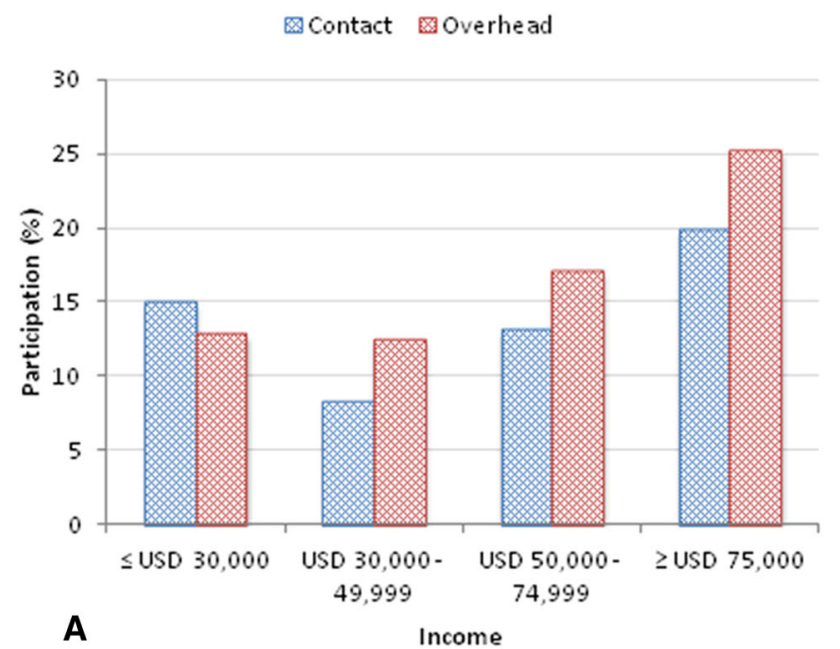

Fig. 3A-B The proportions of (A) males and (B) females in each income group participating in contact and overhead sports are shown. Males with higher incomes were more likely to participate in contact

population toward higher socioeconomic groups. Another limitation is that data for age and income were obtained in a categorical, not continuous manner, meaning that two fairly different individuals could be grouped together (for example, a 31-year-old man making USD 75,000 and a 50year-old man making USD 200,000). Further investigation may be warranted in the relationship of race and ethnicity to shoulder activity, as nonwhite racial groups were underrepresented in our study. Moreover, the relationship of occupation to leisure activity deserves further study. Additionally, a prospective or retrospective cohort study with tighter age ranges and more-even occupational distribution could be used to study changes in activity level during important life transitions (such as graduating from school and joining the workforce, starting a family, retirement). Rather than a one-time assessment of the level of shoulder activity, assessment of changes in the same

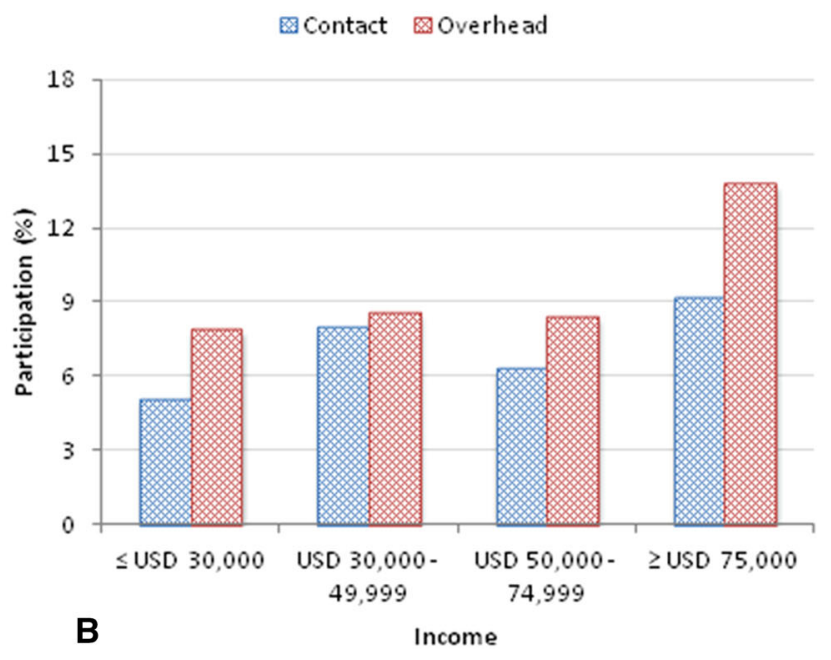

and overhead sports: contact sports $\mathrm{p}=0.006$, overhead sports $\mathrm{p}<$ 0.001. No such difference was seen in females of different income groups: contact sports $\mathrm{p}=0.34$, overhead sports $\mathrm{p}=0.08$.

individual with time or after major life changes might yield important new information that could relate to clinical decision-making and outcomes. Finally, this study population was selected from the United States, required the participants to understand English, and may not be applicable to populations from other countries and cultures.

Higher income levels are associated with higher shoulder activity. This finding is similar to the results of a recent study reporting an association between income level and QuickDASH scores [10]. This association of shoulder activity level with income suggests a mechanism whereby this variable may influence the prevalence of and outcome from shoulder disorders. The trend in activity level related to income may result from numerous possible explanations. Probably the most likely explanation is greater access to, and use of, exercise equipment and recreational activities that stress the shoulder, such as swimming and tennis. 
Because of their elevated shoulder activity, these patients may be more likely to seek treatment for shoulder disorders and less likely to be satisfied with outcomes that do not return them to their preinjury level of activity. More research is needed to better understand how increased shoulder activity level in patients with higher incomes affects their risk for treatment of and outcomes from shoulder disorders.

Shoulder activity level also relates to employment, but not to race or household size. Shoulder activity increases with greater physical demands of employment, which likely puts these individuals at a greater risk for shoulder disorders. In a longitudinal cohort study in Australia, shoulder pain and stiffness were associated with manual work and lower educational attainment [14]. A cross-sectional study in Norway identified physically demanding work and job autonomy as major factors explaining a stepwise socioeconomic gradient for musculoskeletal pain of the lower back and neck-shoulder [18]. A smaller study in the Netherlands found that workers in different construction occupations were at risk for different types of work-related musculoskeletal disorders of the upper extremity [3]. Studies in several countries have identified job-related risk factors for shoulder symptoms such as posture, repetitive work, and type of physical tasks performed [1, 6, 9]. The elevated activity level may be particularly substantial for patients treated while receiving workers' compensation. Patients with workers' compensation claims have been shown to have worse outcomes after rotator cuff repairs [2, 12]. Although these studies adjusted for various factors, neither included shoulder activity level as an explicit variable. Workers' compensation claims also have been associated with worse outcomes after superior labral tear from anterior to posterior (SLAP) repair [8] and acromioplasty [17]. The higher activity level in more demanding occupations could contribute to worse outcomes in these patients and deserves further study.

Our data show that wealthier men are more likely to participate in overhead and contact sports. There may be a confounding effect of employment, as students and retirees are likely to have lower incomes than employed individuals. The elevated activity level in higher income individuals may put them at greater risk for shoulder disorders and make them more likely to seek medical evaluation and treatment for symptoms. It also might make treating these patients more challenging as they are likely to have higher expectations for treatment outcomes. More research is necessary to evaluate exactly how this elevated activity level affects their incidence of, treatment for and outcome from shoulder disorders.

In individuals without shoulder disorders, shoulder activity level is related to socioeconomic factors such as income and type of employment, but not household size or race. Patients who work in more strenuous occupations and have higher incomes probably are more likely to seek treatment for shoulder disorders and may be more challenging to treat because of their elevated activity level. Future research should focus on how elevated activity level in these populations affects the incidence and prevalence of shoulder disorders and the use of care, choice of treatment, and outcomes.

Acknowledgments We thank Karen Steger-May MA (Division of Biostatistics, University of Washington School of Medicine, St Louis, MO, USA) for contributions to the data analysis.

\section{References}

1. Alipour A, Ghaffari M, Shariati B, Jensen I, Vingard E. Occupational neck and shoulder pain among automobile manufacturing workers in Iran. Am J Ind Med. 2008;51:372-379.

2. Balyk R, Luciak-Corea C, Otto D, Baysal D, Beaupre L. Do outcomes differ after rotator cuff repair for patients receiving workers' compensation? Clin Orthop Relat Res. 2008;466:30253033.

3. Boschman JS, van der Molen HF, Sluiter JK, Frings-Dresen MH. Musculoskeletal disorders among construction workers: a oneyear follow-up study. BMC Musculoskelet Disord. 2012;13:196.

4. Brophy RH, Beauvais RL, Jones EC, Cordasco FA, Marx RG. Measurement of shoulder activity level. Clin Orthop Relat Res. 2005;439:101-108.

5. Brophy RH, Levy B, Chu S, Dahm DL, Sperling JW, Marx RG. Shoulder activity level varies by diagnosis. Knee Surg Sports Traumatol Arthrosc. 2009;17:1516-1521.

6. Cassou B, Derriennic F, Monfort C, Norton J, Touranchet A. Chronic neck and shoulder pain, age, and working conditions: longitudinal results from a large random sample in France. Occup Environ Med. 2002;59:537-544.

7. Choi K, Park JH, Cheong HK. Prevalence of musculoskeletal symptoms related with activities of daily living and contributing factors in Korean adults. J Prev Med Public Health. 2013;46:39-49.

8. Denard PJ, Ladermann A, Burkhart SS. Long-term outcome after arthroscopic repair of type II SLAP lesions: results according to age and workers' compensation status. Arthroscopy. 2012;28:451457.

9. Eltayeb S, Staal JB, Hassan A, de Bie RA. Work related risk factors for neck, shoulder and arms complaints: a cohort study among Dutch computer office workers. J Occup Rehabil. 2009;19:315-322.

10. Finsen V. The influence of education and income on responses to the QuickDASH questionnaire. J Hand Surg Eur Vol. 2015;40: 401-405.

11. Gudas R, Kalesinskas RJ, Kimtys V, Stankevicius E, Toliusis V, Bernotavicius G, Smailys A. A prospective randomized clinical study of mosaic osteochondral autologous transplantation versus microfracture for the treatment of osteochondral defects in the knee joint in young athletes. Arthroscopy. 2005;21:1066-1075.

12. Henn RF 3rd, Tashjian RZ, Kang L, Green A. Patients with workers' compensation claims have worse outcomes after rotator cuff repair. J Bone Joint Surg Am. 2008;90:2105-2113.

13. Hepper CT, Smith MV, Steger-May K, Brophy RH. Normative data of shoulder activity level by age and sex. Am J Sports Med. 2013;41:1146-1151.

14. Hill CL, Gill TK, Shanahan EM, Taylor AW. Prevalence and correlates of shoulder pain and stiffness in a population-based 
study: the North West Adelaide Health Study. Int J Rheum Dis. 2010;13:215-222.

15. Kaeding CC, Aros B, Pedroza A, Pifel E, Amendola A, Andrish JT, Dunn WR, Marx RG, McCarty EC, Parker RD, Wright RW, Spindler KP. Allograft versus autograft anterior cruciate ligament reconstruction: predictors of failure from a MOON prospective longitudinal cohort. Sports Health. 2011;3:73-81.

16. Kilgus DJ, Dorey FJ, Finerman GA, Amstutz HC. Patient activity, sports participation, and impact loading on the durability of cemented total hip replacements. Clin Orthop Relat Res. 1991;269:25-31.

17. Lopez JG, Ernst MD, Wright TW. Acromioplasty: comparison of outcome in patients with and without workers' compensation. $J$ South Orthop Assoc. 2000;9:262-266.
18. Mehlum IS, Kristensen P, Kjuus H, Wergeland E. Are occupational factors important determinants of socioeconomic inequalities in musculoskeletal pain? Scand J Work Environ Health. 2008;34:250-259.

19. Ryliskis S, Brophy RH, Kocius M, Marx RG. Shoulder activity level in the preoperative assessment of patients with rotator cuff tears. Knee Surg Sports Traumatol Arthrosc. 2009;17:1522-1528.

20. United States Census Bureau. Current Population Survey Annual Social and Economic Supplement (CPS ASEC) Available at: https://www.census.gov/hhes/www/poverty/publications/pubs-cps. html. Accessed June 10, 2016.

21. United States Census Bureau. American Fact Finder. Available at: http://factfinder.census.gov/faces/tableservices/jsf/pages/productview. xhtml?pid=ACS_09_1YR_S0101\&prodType=table. Accessed June 10, 2016. 